\title{
A morphological and stereological study on calculating volume values of thoracic segments of geese
}

\author{
G. Cakmak, H. Karadag \\ Department of Anatomy, Faculty of Veterinary Medicine, Van Yuzuncu Yil University, Van, Turkey \\ [Received: 30 October 2018; Accepted: 5 December 2018]
}

\begin{abstract}
Background: In this study, the total volume of the thoracic segments of the spinal cord and volume densities of grey matter and white matter were examined by using stereological methods in adult geese having a weight of 3-4 kg.

Materials and methods: Ten geese were used as material without sex discrimination. All animals were perfused with 10\% formaldehyde. In addition, after perfusion, the geese were kept in 10\% formaldehyde for 1 week. Afterwards, thoracic spine was removed and thoracic part of spinal cord was excised. $5 \mu \mathrm{m}$ thick sections were taken from these tissue samples by microtome. The crosssectional series were obtained by sampling from each segment at $250^{\text {th }}$ section. Twelve sections were taken from tissue specimens of every segment. The sections were stained by using haematoxylin-eosin and photographed on a microscope. Results: By using the Cavalieri's Principle, the volume densities (volume fractions) of thoracic segments of spinal cord, volume of white matter, and volume of grey matter in segments were calculated.

Conclusions: In the study, total volume of the thoracic segment, volume of white matter, and the volume of grey matter, and the ratio of these volume values to each other were calculated. The SHTEREOM 1.0 software was used for calculating the volume of section specimens. (Folia Morphol 2019; 78, 1: 145-152)
\end{abstract}

Key words: geese, spinal cord, stereology, thoracic segment, volume

\section{INTRODUCTION}

Stereology is a technique used, not only in biological research, for three-dimentional interpretation of two-dimentional images $[25,27,30]$. Unlike biased methods used in morphometric studies, new stereological methods are "unbiased" [17]. The "efficiency" principle is as much important as the "unbiased" principle in stereological methods [17]. Efficiency can be defined as reaching reliable results in a short time. This principle is based on "Systematic Random Sampling" (SRS) performed for the structures that need to be basically examined under separated components in such sampling, all components of that structure are allowed to be sampled with probability sampling $[17,29]$. Many various methods are used to calcuate total volumes of organs or structures or count components $[8,11,14,20,30]$. The Cavalieri's method is commonly used in stereology to calculate total volume $[12,13,17]$. This method can be applied to calculate the volume of any structure having distinguishable borders macroscopically or at microscopic magnifications regardless of their correlations with their surrounding structures $[12,17]$. It is a frequently preferred method in the stereology to calculate the areas of cross-section images by using a point grid [25]. After counting the total area of

Address for correspondence: Dr. G. Cakmak, Department of Anatomy, Faculty of Veterinary Medicine, Van Yuzuncu Yil University, Van, Turkey, tel: +905061417023, e-mail: vetgamze@hotmail.com 
projections of the examined area in cross-sections, the total volume is calculated by multiplying with the mean thickness of cross-section used to obtain total area value, slices or cross-sections $[7,11]$. The spinal cord (SC) is a part of the central nervous system that controls the voluntary muscles of the limbs and trunk and receives sensory information from these regions. It also controls most of viscera and blood vessels of thorax, abdomen, and pelvis. The cord is made up of a series of segmental components, but it is actually a continuous cylinder of central nervous tissue in adults. The SC occupies most of the cross-sectional area of grey and white matters [10]. The geese belong to the subfamily Anserinae of the family Anatidae from the order Anseriformes of the class Aves [1]. Following the literature review in the study, it was determined that there was a limited number of anatomical studies on morphology of the SC of geese and there was no stereological studies on this subject. The purpose of this study conducted on thoracic segments from the SC of adult geese was to determine grey matter, white matter, and total volume values of thoracic segments. Cavalieri's Principle was used to determine these values. The volume calculations on SC was important because of the lack of volume studies on nervous system of poultry. The obtained volumes and reference findings were determined and presented as original article to contribute to the global knowledge inventory. The aim of this study was to provide basic data for anatomical, histological, stereological and neurobiological studies conducted towards nervous systems of birds.

\section{MATERIALS AND METHODS}

Final report of the research project detailed was approved by Van Yuzuncu Yil University Animal Researches Local Ethic Committee in the session held on 09/29/2016 (Decision Number 2016/09). In this study, 10 healty 1 -year-old geese having a weight of $3-4 \mathrm{~kg}$ were used as material without sex discrimination. Geese were obtained from poultry breeders in Van region. Anaesthesia was applied to them by ketamine hydrochloride (50 mg/kg IP) at anatomy laboratory [2]. For the fixation of the materials, $10 \%$ buffered formaldehyde solution was used by perfusion technique in intracardiac method. The geese were kept in 10\% formaldehyde for 1 week. Soft tissues around the vertebral column were removed. There were 9 thoracic spinal segments in geese. Thoracic spinal segments were separated from other parts of SC.

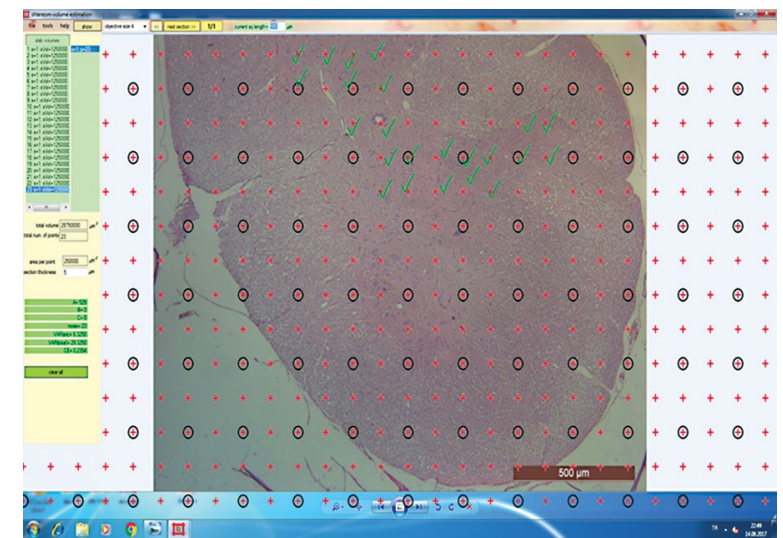

Figure 1. Shtereom 1.0 programme.

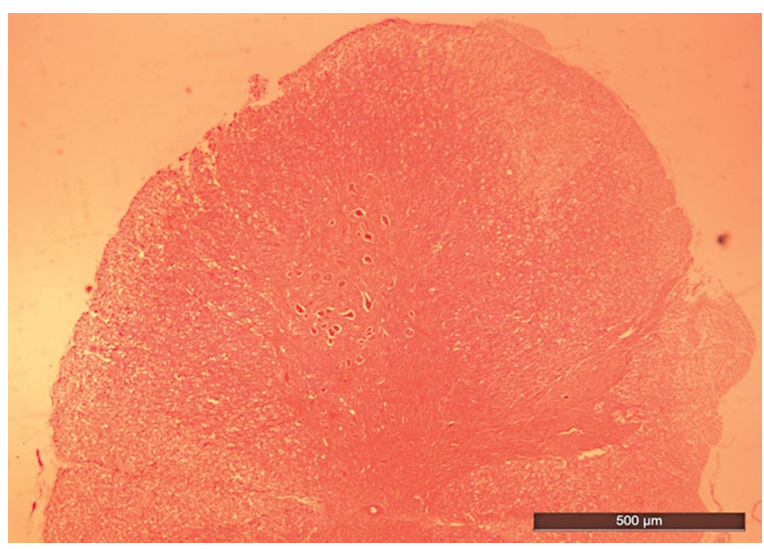

Figure 2. Tissue specimen of the thoracic spinal segment of geese ( $\times 4$ objective magnification).

A pilot study was conducted to determine the number of animals, sections, and sampling. It was determined that SHTEREOM 1.0 Package programme was adequate for this method (Fig. 1) [12]. $5 \mu \mathrm{m}$ thick tissue sections were cut. Averagely, 12 cross-sections were taken from the thoracic segment of the SC of each animal. Sampling was performed systematically and randomly at the ratio of $1 / 250$ by starting from a random one among the first 15 cross-sections and taking following every $250^{\text {th }}$ cross-section. The sections were stained using haematoxylin-eosin staining method and closed by lamellas [19]. The stained sections were photographed at $\times 4$ objective magnification (Figs. 2,3 ). The estimation process was performed using Shtereom 1.0 programme [24]. By using the point field scale at $\times 4$ magnification, surface and volume of white matter, grey matter, and total volume of thoracic segment of geese were estimated (Fig. 1). The number of points were used as volume value of segments [17]. In this study, there is no cross-gender comparison in 


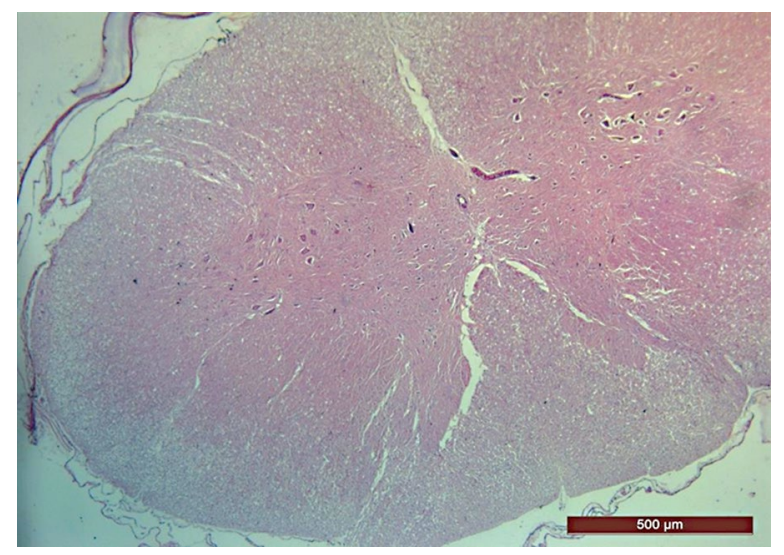

Figure 3. Tissue specimen of the thoracic spinal segment of geese $(\times 4$ magnification).

order to expand the field of study. It will be useful to conduct a study aiming to compare gender-related volume values in thoracic segments.

\section{RESULTS}

When mean volume values of thoracic segment were examined, it was observed that the highest value belonged to the first segment $\left(3.753 \mathrm{~mm}^{3}\right)$. This value decreased beginning from the segment $\mathrm{T} 2$ and the values of the segments T5 and T6 were the lowest ones. While this value was $2.585 \mathrm{~mm}^{3}$ for the segment T5, it was $2.500 \mathrm{~mm}^{3}$ for the segment T6. An increase was determined again for mean values of thoracic volume as from the segment $\mathrm{T} 7$. This value increased to $3.008 \mathrm{~mm}^{3}$ in the segment T9 (Table 1). When the white matter values of the thoracic segment were examined, the first thoracic segment had the highest mean value $\left(2.343 \mathrm{~mm}^{3}\right)$. Mean volume value of the white matter was identified to be 2.139 , 2.091, and $2.039 \mathrm{~mm}^{3}$ for the segments $\mathrm{T} 2, \mathrm{~T} 3$, and $\mathrm{T} 4$. A decrease was revealed in the segments $\mathrm{T} 2, \mathrm{~T} 3$, and $\mathrm{T} 4$ in terms of the white matter values. While the decrease in the value continued also in the segments T5 and T6, a distinct increase was observed in the segment T7. This value was calculated as $2.089 \mathrm{~mm}^{3}$ in the segment T8; whereas, it was $2.110 \mathrm{~mm}^{3}$ in the segment T7. It was observed that the mean volume value of the white matter in the segment T9 was $2.190 \mathrm{~mm}^{3}$ and this value increased in the segment T9. The segment T6 had the lowest value in terms of the white matter volume $\left(1.184 \mathrm{~mm}^{3}\right.$ ) (Table 2). When mean volume values of grey matter in the thoracic segments of geese were examined, it was found that the segment $\mathrm{T} 1$ had the highest value $\left(0.943 \mathrm{~mm}^{3}\right)$.
While mean volume values of the grey matter decreased in the segments $\mathrm{T} 2, \mathrm{~T} 3$, and $\mathrm{T} 4$, the lowest value was $0.587 \mathrm{~mm}^{3}$ and belonged to the segment T5. This value showed a certain increase in this value from the segment T6 to $\mathrm{T} 8$. This value was $0.706 \mathrm{~mm}^{3}$ in the segment T9 (Table 2). When tables of the grey matter/ /the white matter ratio were examined, the highest mean ratio was $0.392 \%$ and belonged to the segment $\mathrm{T} 1$. This value decreased in the segments $\mathrm{T} 2, \mathrm{~T} 3$, and $\mathrm{T} 4$ and increased to $0.366 \%$ in the segment $\mathrm{T} 4$. This value decreased to $0.332 \%$ in the segment $\mathrm{T} 5$. The ratio of the grey matter to the white matter increased in the segment $\mathrm{T} 6$ and decreased again in the segment $\mathrm{T} 7$. While this value was $0.358 \%$ for the segment $\mathrm{T} 8$, it was measured as $0.333 \%$ for the segment T9. The lowest the grey matter/the white matter ratio was $0.332 \%$ and belong to the segment T5 (Table 2). As the white matter/the thoracic SC volume ratio was examined, the highest mean value belonged to the segment T9 and was measured as $0.739 \%$. The lowest value was $0.639 \%$ and increased from the segment $\mathrm{T} 1$ to the segment $\mathrm{T} 7$. While this value was $0.659 \%$ in the segment $\mathrm{T} 2$, it was $0.734 \%$ in the segment $\mathrm{T} 7$. Although the white matter/the thoracic SC volume ratio decreased in the segment $T 8$, this value increased again in the segment T9 (Table 1). When the thoracic segments were examined in terms of the grey matter/ the thoracic SC volume ratio, the segment T6 had the highest volume ratio $(0.258 \%)$. This value was followed by the segment T8 $(0.257 \%)$. The lowest volume ratio belonged to the segment T5 $(0.237 \%)$; whereas, volume ratio of the segment $\mathrm{T} 1$ was $0.246 \%$. While this value of the segment $\mathrm{T} 1$ decreased in the segments $\mathrm{T} 2$ and $\mathrm{T} 3$, it increased in the segment $\mathrm{T} 4$ (Table 1). The newest and unique methods of stereological examinations were applied on thoracic SCs of geese. It was hoped that this study may be a reference study for other anatomical and stereological studies at neuroanatomy on birds. This study was aimed to obtain the basic data about the thoracic segments for neuroanatomy on the poultry. The upper limit for coefficient of error (CE) and coefficient of variation (CV) is 0.05 and 0.10 , respectively [12-15]. Values at Tables 3 and 4 and these limits indicate that the study has a sufficient precision for a typical stereological design. The values calculated at the Tables 3 and 4 showed that the numbers of animals were sufficient for this stereological study. All values of CE under 0.05 and all values of $C V$ were under 0.10 . 
Table 1. Volume values of the thoracic spinal cord of geese (VVSC) $\left(\mathrm{mm}^{3}\right)$, Volume ratios of the white matter/the spinal cord in the thoracic spinal segments of geese (WM/SC) (\%), Volume ratios of the grey matter/the spinal cord in the thoracic spinal segments of geese (GM/SC) (\%)

\begin{tabular}{|c|c|c|c|c|c|c|c|c|c|c|c|c|}
\hline \multirow{2}{*}{$\begin{array}{l}\text { Number of } \\
\text { segment }\end{array}$} & \multicolumn{12}{|c|}{ Number of animal } \\
\hline & & G1 & G2 & G3 & G4 & G5 & G6 & G7 & G8 & G9 & G10 & Means \\
\hline \multirow[t]{3}{*}{$\mathrm{T} 1$} & WSC & 3.208 & 5.230 & 4.272 & 3.532 & 2.975 & 2.291 & 3.568 & 2.398 & 5.577 & 4.483 & 3.753 \\
\hline & WM/SC & 0.702 & 0.506 & 0.550 & 0.646 & 0.696 & 0.692 & 0.640 & 0.755 & 0.653 & 0.557 & 0.639 \\
\hline & GM/SC & 0.198 & 0.261 & 0.225 & 0.225 & 0.210 & 0.268 & 0.257 & 0.236 & 0.297 & 0.286 & 0.246 \\
\hline \multirow[t]{3}{*}{$\mathrm{T} 2$} & WSC & 4.922 & 4.737 & 3.395 & 3.462 & 3.361 & 2.347 & 2.750 & 2.477 & 1.890 & 4.173 & 3.351 \\
\hline & WM/SC & 0.458 & 0.624 & 0.694 & 0.658 & 0.674 & 0.678 & 0.744 & 0.723 & 0.768 & 0.573 & 0.659 \\
\hline & GM/SC & 0.222 & 0.232 & 0.183 & 0.238 & 0.211 & 0.264 & 0.279 & 0.244 & 0.281 & 0.295 & 0.244 \\
\hline \multirow[t]{3}{*}{ T3 } & WSC & 3.492 & 2.570 & 4.097 & 4.570 & 3.343 & 2.582 & 2.232 & 3.693 & 2.506 & 2.158 & 3.124 \\
\hline & WM/SC & 0.709 & 0.734 & 0.618 & 0.614 & 0.678 & 0.673 & 0.685 & 0.618 & 0.773 & 0.673 & 0.677 \\
\hline & $\mathrm{GM} / \mathrm{SC}$ & 0.228 & 0.216 & 0.184 & 0.326 & 0.195 & 0.233 & 0.260 & 0.247 & 0.220 & 0.296 & 0.240 \\
\hline \multirow[t]{3}{*}{ T4 } & WSC & 3.473 & 2.551 & 3.096 & 4.992 & 2.496 & 2.847 & 2.115 & 3.393 & 2.407 & 2.433 & 2.980 \\
\hline & WM/SC & 0.724 & 0.702 & 0.803 & 0.564 & 0.697 & 0.681 & 0.675 & 0.592 & 0.756 & 0.757 & 0.695 \\
\hline & $\mathrm{GM} / \mathrm{SC}$ & 0.223 & 0.204 & 0.184 & 0.340 & 0.231 & 0.251 & 0.279 & 0.277 & 0.210 & 0.286 & 0.248 \\
\hline \multirow[t]{3}{*}{ T5 } & WSC & 3.507 & 2.891 & 3.201 & 2.413 & 2.666 & 2.538 & 1.881 & 2.550 & 2.658 & 1.548 & 2.585 \\
\hline & WM/SC & 0.576 & 0.780 & 0.762 & 0.755 & 0.725 & 0.730 & 0.693 & 0.747 & 0.728 & 0.682 & 0.717 \\
\hline & $\mathrm{GM} / \mathrm{SC}$ & 0.199 & 0.181 & 0.199 & 0.246 & 0.216 & 0.211 & 0.285 & 0.240 & 0.230 & 0.365 & 0.237 \\
\hline \multirow[t]{3}{*}{ T6 } & WSC & 2.878 & 3.212 & 2.930 & 2.462 & 2.436 & 2.867 & 2.297 & 1.767 & 2.393 & 1.765 & 2.500 \\
\hline & WM/SC & 0.628 & 0.746 & 0.854 & 0.722 & 0.770 & 0.742 & 0.723 & 0.702 & 0.757 & 0.681 & 0.732 \\
\hline & $\mathrm{GM} / \mathrm{SC}$ & 0.236 & 0.215 & 0.270 & 0.299 & 0.222 & 0.217 & 0.255 & 0.299 & 0.247 & 0.323 & 0.258 \\
\hline \multirow[t]{3}{*}{$\mathrm{T} 7$} & WSC & 2.905 & 2.893 & 3.318 & 3.505 & 2.658 & 2.862 & 2.203 & 4.106 & 2.077 & 2.433 & 2.896 \\
\hline & WM/SC & 0.696 & 0.777 & 0.850 & 0.679 & 0.762 & 0.721 & 0.676 & 0.625 & 0.735 & 0.824 & 0.734 \\
\hline & $\mathrm{GM} / \mathrm{SC}$ & 0.235 & 0.243 & 0.278 & 0.197 & 0.237 & 0.215 & 0.278 & 0.255 & 0.275 & 0.275 & 0.248 \\
\hline \multirow[t]{3}{*}{ T8 } & WSC & 3.482 & 2.038 & 3.440 & 3.527 & 2.617 & 2.725 & 5.036 & 1.980 & 2.900 & 1.512 & 2.925 \\
\hline & WM/SC & 0.750 & 0.789 & 0.809 & 0.678 & 0.709 & 0.724 & 0.600 & 0.733 & 0.738 & 0.694 & 0.722 \\
\hline & $\mathrm{GM} / \mathrm{SC}$ & 0.196 & 0.311 & 0.257 & 0.195 & 0.212 & 0.256 & 0.256 & 0.258 & 0.271 & 0.361 & 0.257 \\
\hline \multirow[t]{3}{*}{ T9 } & WSC & 4.897 & 1.973 & 3.467 & 3.975 & 3.372 & 2.795 & 2.191 & 1.997 & 3.638 & 1.776 & 3.081 \\
\hline & WM/SC & 0.656 & 0.932 & 0.844 & 0.616 & 0.774 & 0.695 & 0.671 & 0.738 & 0.777 & 0.692 & 0.739 \\
\hline & $\mathrm{GM} / \mathrm{SC}$ & 0.222 & 0.273 & 0.265 & 0.198 & 0.188 & 0.252 & 0.282 & 0.261 & 0.196 & 0.293 & 0.243 \\
\hline
\end{tabular}

\section{Statistical analysis}

In this study, Duncan test was used for statistical analysis. When volume values of the thoracic SC were examined statistically, there was no significant difference between the segments ranging from the segment T1 to the segment T9 (Table 5). It was found that there was no statistically significant difference between the segments T1, T2, T3, T4, T5, T6, T7, T8, and $\mathrm{T} 9$ in terms of volume values of the white matter (Table 5). When volume ratios of the grey matter were examined statistically, it was determined that there was no difference between the segments T2, T3, T4, T7, T8, and T9; whereas, a statistically difference was observed between the segment T1 and the segments T2, T3, T4. $\mathrm{P}<0.01$ and $p<0.05$ were found to be positively correlated with live weights of animals at T3 and T4 segments, respectively (Table 6).

\section{DISCUSSION}

In the study conducted by Begüm et al. [3], on the SC, they segmented the SC along with the vertebral column and then decalcified it. In a study conducted on poultry from the breed leghorn [4], it was reported that segmentation of the SC was not necessary before decalcification and it could be decalcified as a whole. In the present study, the SC was removed by removing arcus vertebrae from vertebral column. Vertebral column was also used as a guide for the segmentation of the SC. In the present study, it was determined that the thoracic area, a part of the SC, could be segmented under the guidance of vertebral column in geese without using decalcification method. The studies $[6,9,10]$ have reported that the number of the thoracic vertebrae is 9 in duck, 9 in goose, and 7 in chicken, pigeon and, quails. In a study 
Table 2. Volume values of the white matter of the thoracic spinal segments of geese (VWWM) $\left(\mathrm{mm}^{3}\right)$, Volume values of the grey matter of the thoracic spinal segments of geese (VVGM) $\left(\mathrm{mm}^{3}\right)$, Volume ratios of the grey matter/the white matter in the thoracic spinal segments of geese (GM/WM) (\%)

\begin{tabular}{|c|c|c|c|c|c|c|c|c|c|c|c|c|}
\hline \multirow{2}{*}{$\begin{array}{l}\text { Number of } \\
\text { segment }\end{array}$} & & \multicolumn{11}{|c|}{ Number of animal } \\
\hline & & G1 & G2 & G3 & G4 & G5 & G6 & G7 & G8 & G9 & G10 & Means \\
\hline \multirow[t]{3}{*}{$\mathrm{T} 1$} & WWM & 2.253 & 2.651 & 2.350 & 2.282 & 2.071 & 1.587 & 2.285 & 1.811 & 3.643 & 2.500 & 2.343 \\
\hline & WGM & 0.637 & 1.368 & 0.963 & 0.798 & 0.625 & 0.616 & 0.918 & 0.566 & 1.657 & 1.283 & 0.943 \\
\hline & GM/WM & 0.282 & 0.516 & 0.409 & 0.349 & 0.301 & 0.388 & 0.401 & 0.312 & 0.454 & 0.513 & 0.392 \\
\hline \multirow[t]{3}{*}{$\mathrm{T} 2$} & WWM & 2.257 & 2.960 & 2.357 & 2.278 & 2.266 & 1.592 & 2.048 & 1.791 & 1.453 & 2.393 & 2.139 \\
\hline & WGM & 1.097 & 1.102 & 0.622 & 0.827 & 0.711 & 0.621 & 0.768 & 0.606 & 0.532 & 1.233 & 0.811 \\
\hline & GM/WM & 0.486 & 0.392 & 0.263 & 0.363 & 0.313 & 0.390 & 0.375 & 0.338 & 0.366 & 0.515 & 0.380 \\
\hline \multirow[t]{3}{*}{ T3 } & WWM & 2.476 & 1.887 & 2.533 & 2.807 & 2.268 & 1.740 & 1.531 & 2.285 & 1.938 & 1.453 & 2.091 \\
\hline & WGM & 0.798 & 0.560 & 0.757 & 1.493 & 0.653 & 0.603 & 0.581 & 0.915 & 0.553 & 0.640 & 0.755 \\
\hline & GM/WM & 0.322 & 0.294 & 0.298 & 0.531 & 0.287 & 0.346 & 0.379 & 0.400 & 0.285 & 0.440 & 0.358 \\
\hline \multirow[t]{3}{*}{ T4 } & WWM & 2.516 & 1.791 & 2.487 & 2.820 & 1.741 & 1.940 & 1.428 & 2.012 & 1.820 & 1.843 & 2.039 \\
\hline & WGM & 0.775 & 0.521 & 0.572 & 1.702 & 0.577 & 0.715 & 0.592 & 0.943 & 0.507 & 0.696 & 0.760 \\
\hline & GM/WM & 0.308 & 0.290 & 0.229 & 0.603 & 0.331 & 0.368 & 0.414 & 0.468 & 0.278 & 0.377 & 0.366 \\
\hline \multirow[t]{3}{*}{ T5 } & WWM & 2.022 & 2.256 & 2.440 & 1.823 & 1.935 & 1.853 & 1.305 & 1.906 & 1.936 & 1.057 & 1.853 \\
\hline & WGM & 0.698 & 0.526 & 0.637 & 0.595 & 0.577 & 0.517 & 0.537 & 0.612 & 0.612 & 0.566 & 0.587 \\
\hline & GM/WM & 0.345 & 0.233 & 0.261 & 0.326 & 0.298 & 0.279 & 0.411 & 0.321 & 0.316 & 0.535 & 0.332 \\
\hline \multirow[t]{3}{*}{ T6 } & WWM & 1.808 & 2.398 & 2.503 & 1.780 & 1.876 & 2.128 & 1.661 & 1.242 & 1.812 & 1.203 & 1.841 \\
\hline & WGM & 0.680 & 0.693 & 0.792 & 0.737 & 0.542 & 0.623 & 0.587 & 0.530 & 0.593 & 0.571 & 0.634 \\
\hline & GM/WM & 0.376 & 0.288 & 0.316 & 0.414 & 0.288 & 0.292 & 0.353 & 0.426 & 0.327 & 0.474 & 0.355 \\
\hline \multirow[t]{3}{*}{$\mathrm{T7}$} & WWM & 2.022 & 2.248 & 2.822 & 2.381 & 2.027 & 2.065 & 1.491 & 2.570 & 1.528 & 2.006 & 2.116 \\
\hline & WGM & 0.683 & 0.705 & 0.925 & 0.691 & 0.631 & 0.617 & 0.613 & 1.051 & 0.573 & 0.671 & 0.716 \\
\hline & GM/WM & 0.338 & 0.313 & 0.327 & 0.290 & 0.309 & 0.298 & 0.411 & 0.408 & 0.375 & 0.334 & 0.340 \\
\hline \multirow[t]{3}{*}{ T8 } & WWM & 2.613 & 1.610 & 2.783 & 2.392 & 1.856 & 1.973 & 3.026 & 1.453 & 2.142 & 1.050 & 2.089 \\
\hline & WGM & 0.685 & 0.635 & 0.887 & 0.690 & 0.556 & 0.700 & 1.293 & 0.511 & 0.787 & 0.546 & 0.729 \\
\hline & GM/WM & 0.262 & 0.394 & 0.318 & 0.288 & 0.299 & 0.354 & 0.427 & 0.351 & 0.367 & 0.520 & 0.358 \\
\hline \multirow[t]{3}{*}{ T9 } & WWM & 3.216 & 1.840 & 2.843 & 2.450 & 2.610 & 1.943 & 1.472 & 1.475 & 2.827 & 1.230 & 2.190 \\
\hline & WGM & 1.092 & 0.540 & 0.920 & 0.788 & 0.636 & 0.706 & 0.618 & 0.523 & 0.716 & 0.522 & 0.706 \\
\hline & GM/WM & 0.339 & 0.293 & 0.323 & 0.321 & 0.243 & 0.363 & 0.419 & 0.354 & 0.251 & 0.424 & 0.333 \\
\hline
\end{tabular}

Table 3. The values of coefficient of variation (CV) of thoracic segments of geese

\begin{tabular}{lccc}
\hline $\begin{array}{l}\text { Segment } \\
\text { numbers }\end{array}$ & $\begin{array}{c}\text { Total } \\
\text { CV }\end{array}$ & $\begin{array}{c}\text { White } \\
\text { matter CV }\end{array}$ & $\begin{array}{c}\text { Grey } \\
\text { matter CV }\end{array}$ \\
\hline T1 & 0.2828 & 0.2299 & 0.3780 \\
T2 & 0.2885 & 0.0200 & 0.2883 \\
T3 & 0.2530 & 0.2046 & 0.3578 \\
T4 & 0.2643 & 0.2015 & 0.4568 \\
T5 & 0.2095 & 0.2079 & 0.0896 \\
T6 & 0.1834 & 0.2197 & 0.1303 \\
T7 & 0.2023 & 0.1866 & 0.2010 \\
T8 & 0.3278 & 0.2835 & 0.2978 \\
T9 & 0.3249 & 0.2979 & 0.2489 \\
\hline
\end{tabular}

Table 4. The values of coefficient of error (CE) for the whole segment, the white and grey matter

\begin{tabular}{lccc}
\hline $\begin{array}{l}\text { Animal } \\
\text { numbers }\end{array}$ & $\begin{array}{c}\text { Total volume } \\
\text { CE }\end{array}$ & $\begin{array}{c}\text { White matter } \\
\text { volume CE }\end{array}$ & $\begin{array}{c}\text { Grey matter } \\
\text { volume CE }\end{array}$ \\
\hline G1 & 0.0201 & 0.0242 & 0.0407 \\
G2 & 0.0221 & 0.0253 & 0.0407 \\
G3 & 0.0203 & 0.0231 & 0.0434 \\
G4 & 0.0203 & 0.0244 & 0.0389 \\
G5 & 0.0220 & 0.0256 & 0.0456 \\
G6 & 0.0204 & 0.0268 & 0.0448 \\
G7 & 0.0233 & 0.0278 & 0.0433 \\
G8 & 0.0231 & 0.0273 & 0.0439 \\
G9 & 0.0225 & 0.0257 & 0.0439 \\
G10 & 0.0245 & 0.0297 & 0.0430 \\
Mean CE & 0.0218 & 0.0259 & 0.0428 \\
\hline
\end{tabular}


Table 5. Statistical analysis of volume values of whole thoracic segment of spinal cord (SC), white matter (WM) and grey matter (GM) (mean \pm standard deviation) and values of GM/WM, WM/CS, GM/CS in the geese

\begin{tabular}{lcccccc}
\hline & $\begin{array}{c}\text { Goose thoracic } \\
\text { SC volume }\end{array}$ & $\begin{array}{c}\text { Goose thoracic } \\
\text { WM volume }\end{array}$ & $\begin{array}{c}\text { Goose thoracic } \\
\text { GM volume }\end{array}$ & $\begin{array}{c}\text { Goose thoracic rate } \\
\text { of GM/WM }\end{array}$ & $\begin{array}{c}\text { Goose thoracic rate } \\
\text { of WM/SC }\end{array}$ & $\begin{array}{c}\text { Goose thoracic rate } \\
\text { of GM/SC }\end{array}$ \\
\hline T1 & $3.753 \pm 0.354$ & $2.343 \pm 0.175$ & $0.943 \pm 0.119^{\mathrm{a}}$ & $0.393 \pm 0.026$ & $0.640 \pm 0.025^{\mathrm{c}}$ & $0.246 \pm 0.010$ \\
T2 & $3.351 \pm 0.322$ & $2.140 \pm 0.139$ & $0.812 \pm 0.078^{\mathrm{ab}}$ & $0.380 \pm 0.024$ & $0.659 \pm 0.029^{\mathrm{bc}}$ & $0.245 \pm 0.011$ \\
T3 & $3.124 \pm 0.264$ & $2.092 \pm 0.143$ & $0.755 \pm 0.090^{\mathrm{ab}}$ & $0.358 \pm 0.025$ & $0.678 \pm 0.017^{\mathrm{abc}}$ & $0.241 \pm 0.014$ \\
T4 & $2.980 \pm 0.264$ & $2.040 \pm 0.136$ & $0.760 \pm 0.113^{\mathrm{ab}}$ & $0.367 \pm 0.034$ & $0.695 \pm 0.023^{\mathrm{abc}}$ & $0.249 \pm 0.015$ \\
T5 & $2.585 \pm 0.181$ & $1.853 \pm 0.129$ & $0.588 \pm 0.018^{\mathrm{b}}$ & $0.333 \pm 0.027$ & $0.718 \pm 0.018^{\mathrm{ab}}$ & $0.237 \pm 0.017$ \\
T6 & $2.501 \pm 0.153$ & $1.841 \pm 0.135$ & $0.635 \pm 0.028^{\mathrm{b}}$ & $0.355 \pm 0.021$ & $0.733 \pm 0.019^{\mathrm{a}}$ & $0.258 \pm 0.012$ \\
T7 & $2.896 \pm 0.195$ & $2.116 \pm 0.132$ & $0.716 \pm 0.048^{\mathrm{ab}}$ & $0.340 \pm 0.014$ & $0.735 \pm 0.022^{\mathrm{a}}$ & $0.249 \pm 0.009$ \\
T8 & $2.926 \pm 0.320$ & $2.090 \pm 0.197$ & $0.729 \pm 0.072^{\mathrm{ab}}$ & $0.358 \pm 0.024$ & $0.722 \pm 0.019^{\mathrm{ab}}$ & $0.257 \pm 0.016$ \\
T9 & $3.008 \pm 0.326$ & $2.191 \pm 0.218$ & $0.706 \pm 0.059^{\mathrm{ab}}$ & $0.333 \pm 0.019$ & $0.740 \pm 0.030^{\mathrm{a}}$ & $0.243 \pm 0.012$ \\
$\mathrm{P}$ & 0.069 & 0.462 & 0.097 & $\mathbf{0 . 6 9 2}$ & $\mathbf{0 . 0 1 8}$ & 0.969 \\
\hline
\end{tabular}

$a, b, c$ The difference between the averages expressed in different letters in the same column is significant

$a, b, c-$ means in the same column followed by different letters are different by the Duncan test $(p<0.05)$.

Table 6. Spearman correlation coefficients between weight and thoracal segments.

\begin{tabular}{|c|c|c|c|c|c|c|c|c|c|c|}
\hline & T1 & T2 & T3 & T4 & T5 & T6 & $\mathrm{T7}$ & T8 & T9 & Weight \\
\hline $\mathrm{T} 1$ & 1 & & & & & & & & & \\
\hline $\mathrm{T} 2$ & 0.183 & 1 & & & & & & & & \\
\hline T3 & -0.316 & 0.093 & 1 & & & & & & & \\
\hline $\mathrm{T} 4$ & -0.304 & 0.141 & $0.845^{* *}$ & 1 & & & & & & \\
\hline $\mathrm{T} 5$ & -0.023 & 0.272 & 0.496 & 0.264 & 1 & & & & & \\
\hline T6 & 0.183 & 0.347 & 0.120 & 0.047 & $0.699^{*}$ & 1 & & & & \\
\hline $\mathrm{T} 7$ & -0.487 & 0.053 & $0.760^{*}$ & $0.693^{*}$ & 0.318 & -0.058 & 1 & & & \\
\hline T8 & -0.111 & -0.176 & 0.141 & 0.088 & 0.087 & 0.234 & -0.224 & 1 & & \\
\hline T9 & -0.071 & 0.140 & 0.551 & 0.494 & $0.663^{*}$ & 0.397 & 0.021 & 0.392 & 1 & \\
\hline Weight & 0.144 & 0.402 & $0.780^{* *}$ & $0.713^{*}$ & 0.606 & 0.567 & 0.430 & 0.287 & 0.605 & 1 \\
\hline
\end{tabular}

${ }^{*} \mathrm{p}<0.05 ;{ }^{* *} \mathrm{p}<0.01$

on morphological characteristics of the SC in chicken, pigeon, and duck, it was stated that the number of the thoracic segments was 6 in pigeon, 7 in chicken, and 8 in duck [16]. Likewise the previous studies, the present study also revealed the presence of 9 thoracic vertebrae in geese. Areas and area ratios of cross-section of the white matter and the grey matter in lumbal segments of the SC were represented as a parameter in morphometric studies on horse $[5,26]$, donkey [21], ape [28], human [18], and rat [22]. The present study revealed morphometric and stereological results by calculating the total volume of thoracic segments, the white matter volume, the grey matter volume and their volume ratios among geese. In the study by Hazıroğlu et al. [16], it was determined that area values of the segment $\mathrm{C} 4$ in chicken and duck were larger compared to the other segments and the white matter/the grey matter ratio of the segment $\mathrm{C} 1$ was lower than the other segments. When the grey matter/the white matter volume ratio of the thoracic segments was examined in the present study, it was found that while the highest value belonged to the segment $\mathrm{T} 1$, the segment $\mathrm{T} 5$ had the lowest ratio. Rahmanifar et al. [23] reported that the thoracic part had the minimum amount of the grey matter in adult ostrich. Similar to the results of the study by Rahmanifar et al. [23]; even though volume values of the grey matter of the thoracic segments in geese were generally low in the present study, mean volume value of the white matter was higher compared to 
the grey matter. In a study on poultry [4], the cervical enlargement was stated to be composed of $\mathrm{C} 13, \mathrm{C} 14$, $\mathrm{C} 15$, and $\mathrm{T} 1$ and $\mathrm{T} 2$. The present study also revealed that the segments $\mathrm{T} 1$ and $\mathrm{T} 2$ involved in the formation of the cervical enlargement area. In a study by Haziroğlu et al. [16], it was explained that the cervical enlargement was shaped by the segments $\mathrm{C} 13, \mathrm{C} 14$, $\mathrm{C} 15, \mathrm{~T} 1$ and $\mathrm{T} 2$ in chicken, the segments $\mathrm{C} 12, \mathrm{C} 13$, $\mathrm{C} 14, \mathrm{C} 15, \mathrm{~T} 1$ and $\mathrm{T} 2$ in duck, and the segments $\mathrm{C} 11$, $\mathrm{C} 12, \mathrm{C} 13, \mathrm{~T} 1$ and $\mathrm{T} 2$ in pigeon. In the present study. it was determined that the segments $\mathrm{T} 1$ and $\mathrm{T} 2$ involved in the formation of the cervical enlargement.

\section{CONCLUSIONS}

In conclusion, it was determined that all segments, the grey matter and the white matter showed differences between the thoracic segments of the SC in terms of volume values and these differences caused statistically significant results. It was revealed that it was possible to calculate volumes of the grey matter and white matter in the thoracic part of the SC in geese from poultry by using stereological methods and more correct data could be obtained using physical dissector method while making all these calculations. It was also found that the sampling method used in the present study might remain insufficient to calculate parameters such as volume and number concerning whole $\mathrm{SC}$ as used for the thoracic part of the $\mathrm{SC}$ and it was needed to determine a sampling strategy for each segment as in the present study. It was thought that repeating the available studies, on the segment of the poultry evaluated with previous methods, within the scope of stereological methods would make contribution to the science. The requirement of CE of $10 \%$ or below in calculation of the volume values using Cavalieri's principle is accepted as an important parameter in terms of the reliability of the study $[12,15]$. In the present study, CE was evaluated individually for calculations of total segment volume, the grey matter volume and, white matter volume and this value reported was reliable. As a result, it was seen that total volume of the thoracic segment was the highest at first thoracic segment. And the white matter of the thoracic segment had the highest volume at first thoracic segment. Also, volume of the grey matter was the highest at first thoracic segment. It was shown that total volume of the thoracic segment, volume of the white matter, and the grey matter were parallel at the first thoracic segment. The lowest volume of the thoracic segment was observed at sixth thoracic segment. The white matter had the lowest volume value at sixth thoracic segment. But the lowest volume of the grey matter was observed at fifth segment. Upon the literature review, any data about stereological study could not be found. So, there was no reference literature about stereological study on the thoracic segments of geese. This study revealed volume values of the white and grey matters and total volume of the thoracic SC of geese by using the Cavalieri's Principle, which is the last stereological and morphometric method. We believe that the results of this study may be used as a reference data. It was especially determined that stereological data, obtained as a result of the study, made a significant contribution to calculation of volume values of the area by evaluating these data within themselves. In this study, there was no gender comparison in order not to expand the field of study. It would be useful to conduct a study aiming to compare gender-related volume values of thoracic segments.

\section{Acknowledgements}

Presidency of project scientific research of Van Yuzuncu Yil University was source of funding for this study. Project code: 2011-VF-B26/ ID: 838.

\section{REFERENCES}

1. Anonymous. https://www.britannica.com/animal/goosebird (09/01/2017).

2. Aslanbey D, Sağlam M, Gürkan M, et al. General anesthesia with ketamine in wings. Vet J Ankara Uni. 1987; 34: 288-299.

3. Begum F, Zhu W, Namaka MP, et al. A novel decalcification method for adult rodent bone for histological analysis of peripheral-central nervous system connections. J Neurosci Methods. 2010; 187(1): 59-66, doi: 10.1016/j. jneumeth.2009.12.013, indexed in Pubmed: 20043948.

4. Bolat D. Examination of spinal cord by stereological methods in leghorn wings. Doctoral dissertation, Selçuk Uni, Health Sciences Institute, Konya. 2011.

5. Braun $A$. Der segmentale feinbau des rückenmarks des pferdes. Acta Anat Basel. 1950; 10: 1-76.

6. Can M, Özdemir D, Özüdoğru Z. Macro-anatomical studies on the skeletal system of the teal. (Anas crecca) I. skeleton axiale. Ataturk Uni J Vet Sci. 2010; 24: 123-127.

7. Canan S, Sahin B, Odacı E, et al. et al.. A stereological method used to calculate total volume, volume density and volume ratios: Principle of Cavalieri. Clinc Turkey J Med Sci. 2002; 22: 7-14.

8. Cruz-Orive LM, Weibel ER. Recent stereological methods for cell biology: a brief survey. Am J Physiol. 1990; 258(4 Pt 1): L148-L156, doi: 10.1152/ajplung.1990.258.4.L148, indexed in Pubmed: 2185653.

9. Doğuer S, Erençin Z. Comparative anatomy of domestic birds. Ankara University Faculty of Veterinary Textbooks, Publisher of University of Ankara, Ankara. 1964. 
10. Dursun N. Anatomy of domestic birds. Medisan, Ankara 2002: 97-98.

11. Gundersen HJ. Stereology of arbitrary particles. A review of unbiased number and size estimators and the presentation of some new ones, in memory of William R. Thompson. J Microsc. 1986; 143(Pt 1): 3-45, indexed in Pubmed: 3761363.

12. Gundersen HJ, Jensen EB. The efficiency of systematic sampling in stereology and its prediction. J Microsc. 1987; 147(Pt 3): 229-263, indexed in Pubmed: 3430576.

13. Gundersen HJG, Bendtsen TF, Korbo L, et al. Some new, simple and efficient stereological methods and their use in pathological research and diagnosis. APMIS. 1988; 96(1-6): 379-394, doi: 10.1111/j.1699-0463.1988.tb05320.x.

14. Gundersen $H$, Bagger $P$, Bendtsen $T F$, et al. The new stereological tools: Disector, fractionator, nucleator and point sampled intercepts and their use in pathological research and diagnosis. APMIS. 1988; 96(7-12): 857-881, doi: 10.1111/j.1699-0463.1988.tb00954.x.

15. Gundersen HJ, Jensen EB, Kiêu K, et al. The efficiency of systematic sampling in stereology--reconsidered. J Microsc. 1999; 193(Pt 3): 199-211, indexed in Pubmed: 10348656.

16. Haziroglu RM, Orhan IO, Yildiz D, et al. Morphology of the spinal cord in the chicken. duck and pigeon. Turk J Vet Anim Sci. 2001; 25: 913-920.

17. Howard CV, Reed MG. Unbiased stereology: three-dimensional measurement in microscopy. Vol 2. Taylor \& Francis 2015: 34-39.

18. Ko HY, Park JH, Shin YB, et al. Gross quantitative measurements of spinal cord segments in human. Spinal Cord. 2004; 42(1): 35-40, doi: 10.1038/sj.sc.3101538, indexed in Pubmed: 14713942.

19. Luna LG. Manual of histologic staining methods of the armed forces institute of pathology. IN Luna LG (ed) McGraw- Hill Book Company, New York. 1968: 199-200.

20. Mayhew TM, Gundersen HJ. If you assume, you can make

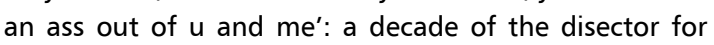

stereological counting of particles in 3D space. J Anat. 1996; 188 ( Pt 1): 1-15, indexed in Pubmed: 8655396.

21. Öcal MK, Hazıroğlu RM. Comparative morphologic investigations on spinal cord of donkey (Equus asinus L.). I. Examination of transversal sections of segments. Vet J Ankara Uni. 1988; 35: 55-68.

22. Portiansky EL, Barbeito CG, Goya RG, et al. Morphometry of cervical segments grey matter in the male rat spinal cord. J Neurosci Methods. 2004; 139(2): 217-229, doi: 10.1016/j.jneumeth.2004.04.031, indexed in Pubmed: 15488235.

23. Rahmanifar F, Mansouri S, Ghazi S. Histomorphometric study of the spinal cord segments in the chick and adult male ostrich (Struthio camelus). Iranian J Vet Res. 2008; 9: 336, doi: 10.22099/IJVR.2008.2615.

24. Roberts N, Hogg D, Whitehouse G, et al. Quantitative analysis of diurnal variation in volume and water content of lumbar intervertebral discs. Clin Anat. 1998; 11(1): 1-8, doi: 10.1002/(sici)1098-2353(1998)11:1<1::aidca1>3.0.co;2-z.

25. Russ JC, Dehoff RT. Practical stereology. In: Russ J.C., Dehoff R.T (ed). Plenum Press, New York 1999.

26. Selçuk ML. Morphometric investigations on lumbal segments of spinal cord in horses. Master Dissertation. University of Selçuk, Health Sciences Institute, Konya. 2011.

27. Sterio DC. The unbiased estimation of number and sizes of arbitrary particles using the disector. J Microsc. 1984; 134(Pt 2): 127-136, indexed in Pubmed: 6737468.

28. Thomas CE, Combs CM. Spinal cord segments. B. Gross structure in the adult monkey. Am J Anat. 1965; 116: 205-216, doi: 10.1002/aja.1001160110, indexed in Pubmed: 14283282.

29. Unal B, Aslan H, Canan S, et al. Significant sources of error in the old (sided) methods used when counting objects in biological environments and suggestions for solutions. Clinc Turkey J Med Sci. 2002; 22: 1-6.

30. Weibel ER. Stereological Methods. Vol. 2: Theoretical Foundations. Academic Press Inc., London 1980. 